\title{
The impact of the random urban sprawl on the master plan of the city of Baquba
}

\author{
Hassoon Allawi Hassoon \\ Department of Architectural Engineering, College of Engineering, University of Diyala \\ hassounam2000@gmail.com
}

\begin{abstract}
Population growth and irregular migration to urban centres in a manner inconsistent with what is planned and the reality of the master plan of the city of Baquba one of the main causes of the problems of housing violations and their impact on the environment of the city, Where the agricultural areas were bulldozed for the purpose of transforming them into residential areas, exacerbating the city's problems in meeting the public services. The research includes first the causes of the violations on the master plan and secondly the areas exceeded and thirdly the effects of the repercussions and problems resulting from the urban society of the city as a result of this overrun and proposed solutions to modify the master plan to accommodate these abuses and the development of the new master plan for the future residential expansion and development and modification of the master plan of the city to meet the requirements Urbanization.
\end{abstract}

Keywords: - urbanization, master plan, residential areas.

Paper history: (Received: 15/11/2017; Accepted: 24/6/2018)

\section{Introduction}

Baquba is characterized by the cultivation of palm trees and fruit trees. Their trade depends on the fruits transported to Baghdad markets. The city, like other cities in Iraq, suffered the exceptional problems and circumstances and a serious violation of laws and regulations because of political, economic and sectarian conflicts that led to arbitrary expansion and violation of laws and regulations for city planning and master plan of the city. Therefore, we found that we identify the causes of these abuses and put solutions to restore normal life and natural growth to expand the outline of the city of Baquba in a deliberate and orderly and to develop plans and future solutions to the problems of urbanization of the city of Baquba.

\section{Research importance}

To clarify the phenomenon of random urbanization on the city's master plan. Identification of exceeding areas, overruns, causes and type of random sprawl.

\section{Research goals}

Defined the necessary solutions to the effect of the violations on the internal structure of the city and to stop the excesses and solve the problem causing random abuses on the master plan of the city

\section{Descriptive analytical method}

To clarifying and studying the history of random urban sprawl, it has been followed analytically on a scientific basis according to the data:

1- Previous studies.

2. Questionnaires of citizens from areas where residential sprawl occurred.

3 - Information documented by the Municipality of Baquba and the Planning

Department of the city of Baquba statistics of the demographic change in the city and its impact on the areas and housing units that have been exceeded.

4 -The field survey of the sprawl residential areas.

\section{Literature Theoretical Review}

The increase in the population of the city as a result of migration to the city from the surrounding areas for many reasons is difficult to control, and the growth of the city in this way may affect the balance of living of the population in an acceptable manner. The increase in population due to natural increase and rural migration have visible effects and are negative or positive. The political, economic and social changes that took place after 2003 in Iraq and the deterioration of the security situation and its impact on the city and its manifestations is the indiscriminate urban expansion of the basic design in most cities of Iraq :

1- The population growth rate for the period from 1997 to 2009 reached 2.4\% .The city of Baquba doubled its population after it did not exceed (10371) people in the 1947 census increased to (144052) people in the 1987 census and then reached (563789) .This situation is not considered and is not expected due to the deterioration of the security situation in Diyala governorate since 2003, which has serious disadvantages, most notably the phenomenon of the forced displacement of villages and entire cities to the city of Baquba. According to statistics of the Department of Migration and Displacement in the province of Diyala, the displacement of more than (6700) families towards the city of Baquba until March 2015 and the impact of mass exodus and pressure on the housing sector and services in Baquba (Table 1).

2 - The inability of housing units and the low standard of living of most of the population as a result of the economic blockade after the second Gulf war in 1990, prompting the owners of residential units to divide their units into smaller units for the purpose of renting or solve the housing crisis 
for the family itself ${ }^{(4)}$. 3 - Lack of housing projects since the nineties, only one complex of low-income housing area in the forest area southwest of the city with an area of 64 acres consisting of (632) housing units and the work of this project in the final finishing phase for more than a year.

4 - The high rate of unemployment, which reached (16.3\%) in 2015 as a result of the dissolution of the army and the military industrialization, which led to an increase in the number of unemployed and some of them to divide their units for the purpose of renting .

5 -The decline of local authorities in investment in the housing and services sectors due to poor security conditions and financial and administrative corruption ${ }^{(9)}$, for example the heavy water treatment plant and multistorey residential complexes in the city ${ }^{(5)}$.

6. The low level of agricultural production due to the weak political situation, which

reflects the weakness of agricultural policy and the scarcity of water resources due to the establishment of dams on the Diyala River and its tributaries, as well as the spread of agricultural diseases ${ }^{(10)}$.The poor pest control mechanism reduced agricultural production and led to the death of large numbers of fruit trees, encouraging farmers and orchards to bulldoz their own orchards and sell them as residential land ${ }^{(1)}$.

7. The inability of government agencies to stop abuses and limit their spread. On the contrary ${ }^{(11)}$, laws were issued in favour of those who infringe by the ownership of the most important offenders: Law No. (397) of 1970 and Law No. 721 of 1971 and the Law of 1987 stipulating that owners of agricultural land and orchards To construct residential houses for them And their children with an area of $300 \mathrm{~m}$ 2 for the owner of the land and $200 \mathrm{~m} 2$ for each of his children, which led to the growth of random housing in the Agricultural areas of Baquba and then followed by Law (154) for the year 2001 and the law (156) for the year 2003 which content for the benefit of the transgressors.

8. The modifications made in 2006 to the basic design were not appropriate or realistic ${ }^{(12)}$, as they defined the expansion of the city to the east, especially for residential use without services and no plans to provide services ${ }^{(7)}$.

9 - The turnout of citizens after 2003 on the possession of housing units within the relatively expensive city centre, which forced them to buy small housing units and the construction of small residential units unlicensed ${ }^{(13)}$, a general problem caused by the lack of supervision and nonimplementation of laws and conditions of construction ${ }^{(14)}$.

\section{Research problems}

Amendments made in 2006 to the basic design of the city of Baquba in 1994, which determined the area of residential use $(69 \%){ }^{(2)}$. The site survey revealed that random construction spread throughout the city ${ }^{(6)}$. The percentage of overruns varied from one region to another, which is related to the relationship of overflow with the existence of empty spaces inside the residential areas, which are within the master plan for public services. Urban sprawl on occupied agricultural land or green areas ${ }^{(8)}$. (Table 2) (Table 1).

1 - Urban sprawl was distributed in one place to form new neighbourhoods within the existing residential neighbourhoods ${ }^{(3)}$.

2 - The excesses within the residential neighbourhoods occupied on vacant spaces for city services.

3 - Excesses are a modification of the residential unit at the expense of the garden or converted to an apartment.

\section{Residential neighbourhoods and urban sprawl}

The spatial boundaries of the areas and residential neighborhoods in Baquba city were represented by the municipal boundaries of the city of Baquba, Diyala Governorate, according to the basic design of the city of Baquba in 1994 and its amendments for the year 2006 (Plan 1) (Table 1). In the most neighborhoods of Baquba, random dwellings were concentrated in addition to the residential encroachments that were constructed and formed new neighborhoods within the residential neighborhoods themselves (Plan 2) (Table 2):

(1) Yarmouk second district: west of the city with a total area (574.5 hectares) was the first type of excess, where the sprawl of residential (1918) housing units exceeded. In this district and the first Yarmouk district, 698 housing units were occupied (91)ha.

The majority of the housing units were built in a random manner with low construction specifications and simple building materials. Most of the residents are connected by relatives and rural assets. Most of them have no fixed income and live at a low economic level. The other group is in the southern part. It is called the village of the displaced. The number of its units reached 204 units. Usually with low specifications and living in continuous growth currently occupying 2 ha.

(2) Hattin district: the oldest and largest neighbourhood of sprawl in the city of Baquba, it began to exceed 1959 through the construction of mud houses and roofing Palm palm trees or wood. And lacks the most basic elements of life as well as contain the remains of animal breeding district is located east of the city of Baquba, not far from the city centre $(2 \mathrm{~km})$. The area of the neighbourhood $(48$ hectares) and (1016) housing units were added within the amendments in 2006 on the basic design for the year 1994.

(3) Shifta neighbourhood: This neighbourhood is located on the eastern side of the city of Baquba on the left bank of the river Diyala and is a small neighbourhood (42 hectares). The residential excesses in this neighbourhood are among the most dangerous violations. They were built on the most fertile agricultural land that for hundreds of years was known for the cultivation of citrus and palm trees. And in the absence of law in 2003, these orchards 
were bulldozed by their owners and sold as residential plots. And built the excesses in this neighbourhood with the latest urban models, some of them to the palaces and most of the population of senior officials of the state and enable them by virtue of their influence to deliver services to this neighbourhood and their excesses at their own expense.

(4) Al-Mustapha neighbourhood: Located on the western side of the city of Baquba on the Yemeni bank of the Diyala River and is followed by citrus orchards from the east and south. The residential urban sprawl built with high architectural specifications on the land of orchards. The housing units were not constructed in an organized manner and linked to closed-end streets. And the phenomenon of residential units divided into several housing units.

(5) Al-Tahrir Second Quarter: This district is located in the south-eastern part of the city of Baquba with an area of (228.2) ha. The existence of agricultural land and empty land encouraged the existence of housing abuses.

(6) Al-Saray neighbourhood: Located in the eastern part of the city on the left bank of the river Diyala and the nucleus of the old city houses a heritage of the central courtyard and the eastern building the extent of excesses reached (287) housing units occupied fruit orchards after the bulldozing after 2003 .

(7) Mothers of the Bone and the Industrial Quarter: The indiscriminate excesses and their building materials in the simplicity of their rural construction and in their distribution and overlapping uses between them. A heterogeneous urban landscape Most of the residents of this neighbourhood are of rural origin and do not like housing in small residential units.

\section{Results and discussion}

The speed of residential excesses creates obstacles that are difficult to overcome when the processing mechanisms are delayed: (Plan No. 2).

1 - A sharp decline in the economy of the city, according to the statistics of the cultivation of Baquba centre to the loss of more than (5572) acres of orchards of the city of Baquba and neighbouring villages. And that most of the horticultural land turned into residential units whose production of fruit and dates covered the Iraqi market.

2 - The lack of homogeneity of urban construction in the city of Baquba, which spread in neighbourhoods such as Yarmouk first and second Hattin and the first liberation, which is a residential unit built with different materials such as mud, blocks and tin, and a shovel of wood and randomly in the heart of residential neighbourhoods and the nature of narrow twisted streets . Linking it to what gave the city a homogeneous and distorted urban landscape.

3 - Urban expansion is a formidable burden on all types of services, especially electricity and potable water.There are three stations feeding the city of Baquba with electricity designed to carry a forced load (174) megawatts while the load does not exceed (82) megawatts. With the expansion of random increased the problem of lack of electricity service in all neighbourhoods of the city, which reached (12) hours during the summer. In spite of the presence of a main station feeds most of the city's neighbourhoods and the existence of four substations (combined units), but the interruption of water in some neighbourhoods lasts from three to four days during the summer. A study on the presence of water scarcity in the neighbourhood of Shifta almost lasts the length of the summer and that water scarcity is linked to the existence of housing abuses north of this neighbourhood, which reduced the arrival of water to the southern regions.

4 - Pressure on all health services, educational and municipal, especially in neighbourhoods where high random expansion, for example, high hopes for girls in the Tahrir district the number of female students in the one to (45) students, some of them sitting on the ground as well as the middle of Iraq for boys in the neighbourhood of Mustafa and the beginning of his mixed lips .

5 - The existence of some negative phenomena, including begging of the population of rural origins in most streets of the city and its main intersections and markets and multiply this phenomenon in a systematic manner and that (98\%) of these beggars are women and children and most of them residents of the suburbs located south - To a safe haven for lawbreakers. As well as the emergence of child labour is another face for begging, such as the sale of water and napkins in the streets and intersections of the city, which expose them to deviation and affect negatively on the safety of urban society.

6 - The phenomenon of urbanization by some of those who exceed the raising of animals in their homes and leave them to graze outside the house and on household waste, especially in the neighbourhoods of Hattin, Um Al-Azmi, Yarmouk I and II and Mafraq 14, as well as in the finest neighbourhoods of the city such as Al-Mustafa and Baquba new.

7 - The phenomenon of environmental pollution of various types, the residential excesses expose a lot of household waste on a daily basis, which the municipal authorities cannot remove on a daily basis. As for the visual pollution, the occupants of the residential communities use different and heterogeneous building and finishing materials and unplanned designs with existing residential structures, resulting in a distorted urban landscape. The removal of many orchards and green areas within the city expands the phenomenon of desertification and soil degradation and deprives the environment of its green belt, which has a major role in the purification of the city air. 8 - Random urbanization, alteration of urban land use and overriding the basic design of the city have resulted in poor efficiency of the civil services provided to the population. 
9 - Population growth, migration and displacement suffered by the city led to the emergence of these abuses, especially the abuse of housing

10 - The indiscriminate urbanization of the agricultural areas of fruit orchards fertile soil, which is difficult to remove and even if removed, it does not return the city to its green belt, bordered from north to south.

11 - The weakness of the role of municipal supervision and the absence of state authority after the events of 2003 and administrative corruption has a major role in the spread of urban expansion indiscriminately in all neighbourhoods of the city of Baquba.

12 - The indiscriminate urbanization in the city of Baquba led to a sense of urban population of urban suffocation and loss of aesthetic space that was added orchards adjacent to the Diyala River on the city of Baquba.

\section{Recommendations, suggestions and solutions}

1 - The development of treatments and policies to rehabilitate random urban expansions and stop the residential encroachment on orchards and the enactment and enforcement of laws criminalize the process of bulldozing orchards and strict penalties against violators by the authorities in charge of local authority.

2 - Develop and implement vertical residential projects for people with low income through the state or by encouraging investment to reduce the phenomenon of slums.

3 - Putting deterrent penalties to stop the phenomenon of division of housing units and activate the role of the municipality to implement legislation to be more effective.

4 - Issuing basic design schemes that take account of changes and societal changes, and that these schemes do not constitute models or create another problem and educate citizens to abide by the basic plans in order to live in a healthy urban environment.

\section{References}

[1] Kamouna, Haidar Abdul Razzaq and. Al-Azzawi, Wadad Salman, urban creep on the green areas and its environmental effects on the city of Baghdad, Journal of Planning and Development, No. 21, 2009 p 20.

[2] Allawi Kazem, Unemployment in Iraq, Reality, Archeology, Mechanisms of Obstetrics and
Treatment, Kufa University, Faculty of Management and Economics, 2011 p 10.

[3] Mohammed Yousef Al-Hiti, Baquba City, a study of its internal structure, a master's thesis, unpublished, Faculty of Education ibn Rushd, University of Baghdad, 1989 p 1.

[4] Department of Migration and Displaced Diyala Governorate 2015.

[5] Diyala Housing Department 2010.

[6] Hassana Nasser Ibrahim, Unemployment and the creation of work one of the challenges of the current situation, Journal of Baghdad College of Economic Sciences No. 29, 2009, p. 71.

[7] Directorate of Urban Planning Diyala Governorate, report on the 2006 amendments to the basic design of the city of Baquba for the year 1994.

[8] Baquba Agriculture Division.

[9] Electricity Distribution Department in Baquba City, Technical Section, 2015.

[10]Diyala Water Directorate, Technical Commission Division.

[11]Diyala Governorate Traffic Directorate, 2014 data.

[12]Dr. Shueh Majid Hamid, d. Raja Khalil Ahmed, Baquba City, the violations of the basic design of the city of Baquba, University of Diyala, Faculty of Education for Human Sciences / Department of Geography.

[13] Ahmed Saeed Fadhil, Commercial Position of Baqubah City and Areas of Commercial Influence in Diyala Governorate, $\mathrm{PhD}$ Thesis, University of Diyala, Faculty of Education for Human Sciences, 2014.

[14] Owners of land sales offices in the new neighbourhoods of Baquba, Yarmouk II, Shefta, Mustafa, 2017

[15] Reference to research published in Diyala Journal of Engineering Sciencies(The impact of the regulatory problems facing the transport network on the urban growth of Baquba) Diyala Journal-10 No-9-No 4December 2017.

[16] Reference to research published in Diyala Journal of Engineering Sciencies(The impact of blocking the streets on the environmental pollution of the city of BAGHDAD) Diyala Journal of Engineering Sciences10-N012-No-4 December 2017. 


\section{Charts and tables}

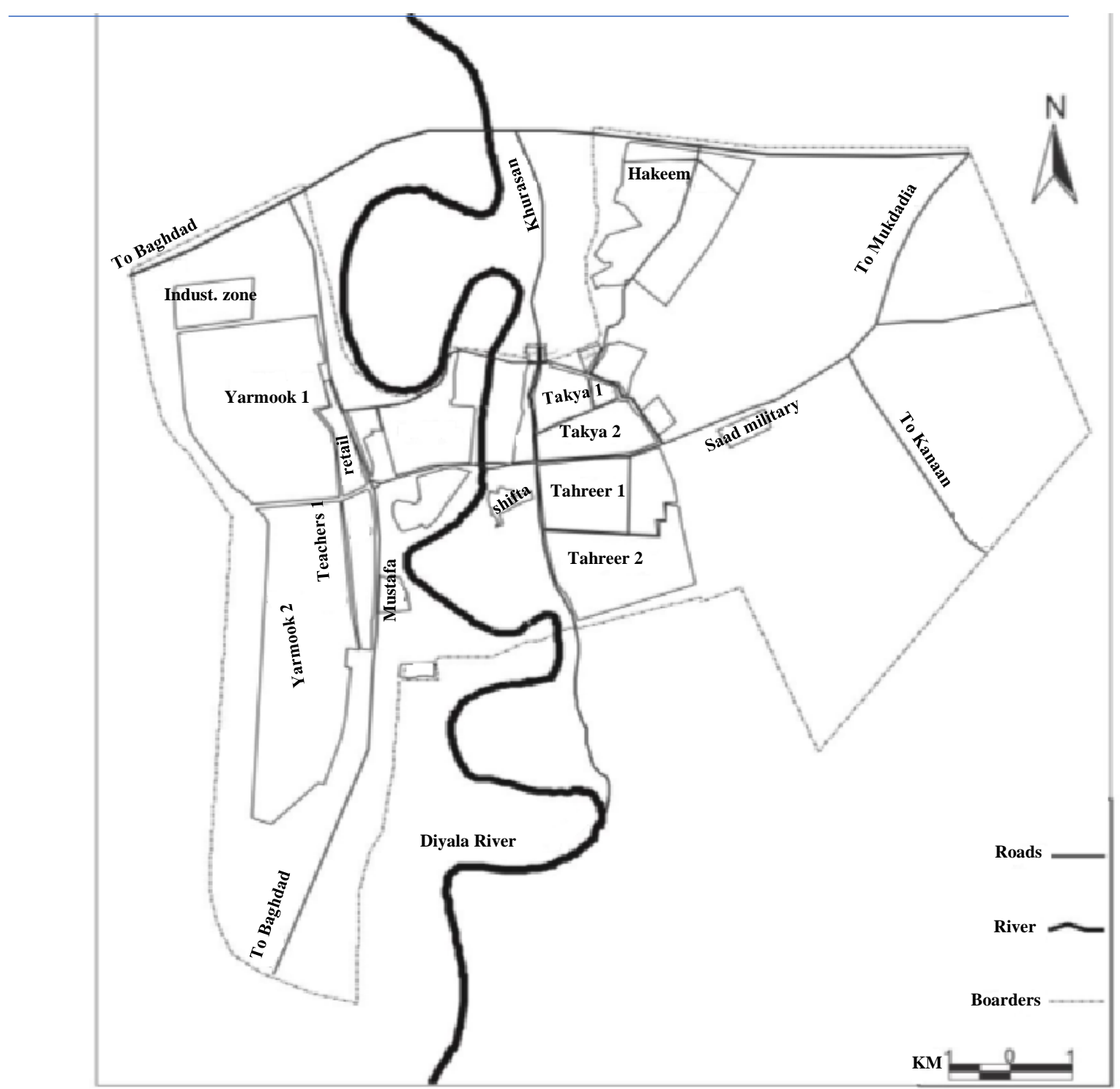

plan (1): - Map of the areas of the city of Baquba in $2015^{(7)}$ 


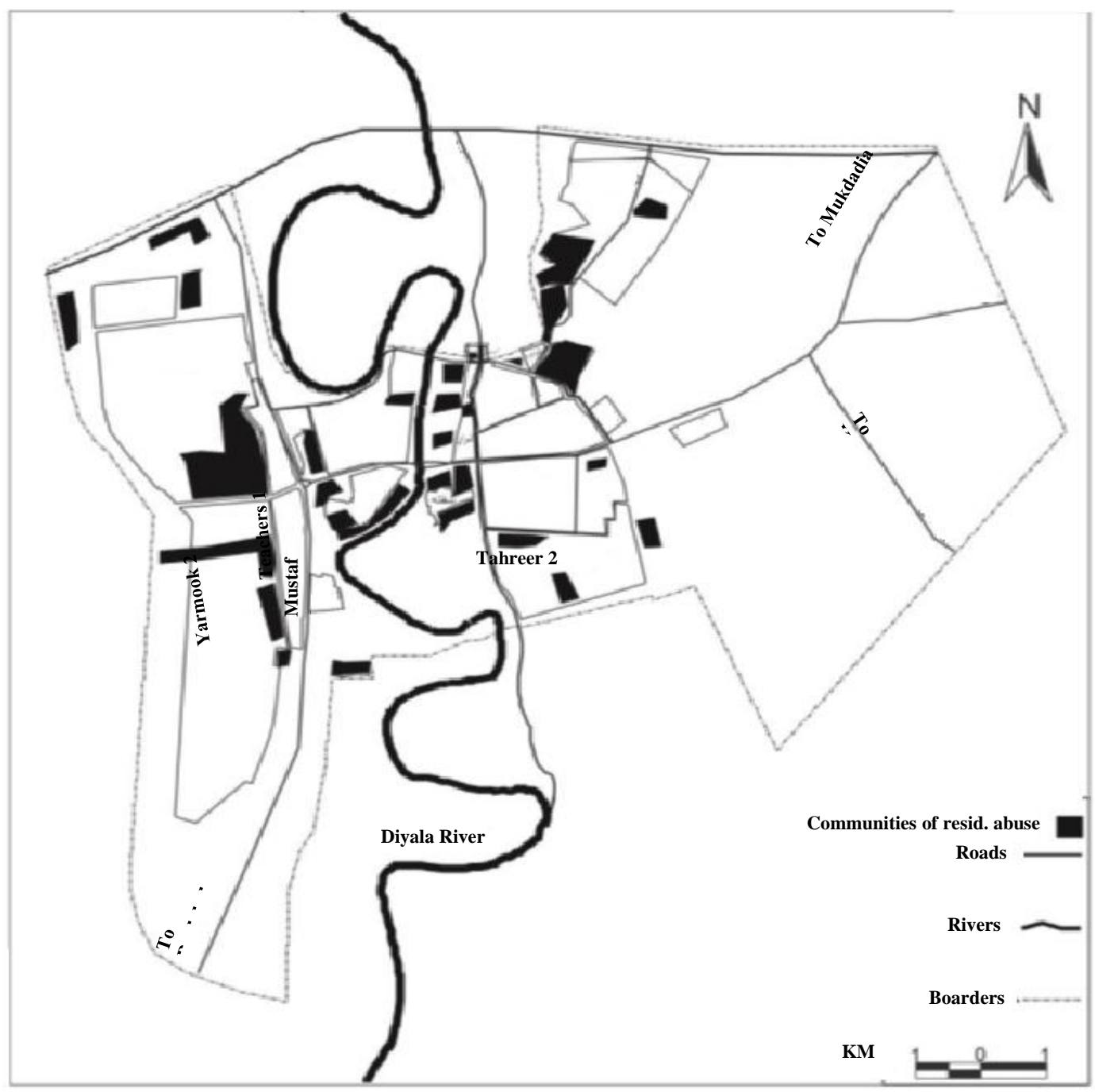

plan (2): Map of the urban expansion of the city of Baquba for the year $2015^{\text {(7) }}$

Table (1): Population, Area of Living and Number of Housing Units in Baquba City, 2014 (5)

\begin{tabular}{|c|l|c|c|c|c|c|}
\hline No. & neighborhood name & Population & $\begin{array}{c}\text { Living } \\
\text { area }\end{array}$ & $\begin{array}{c}\text { number of } \\
\text { units }\end{array}$ & $\begin{array}{c}\text { Population } \\
\text { density }\end{array}$ & $\begin{array}{c}\text { Population } \\
\text { density }\end{array}$ \\
\hline 1 & First Tekiya & 18469 & 74.3 & 8.9 & 248.5 & 10.8 \\
\hline 2 & Second Tekiya & 8209 & 104.6 & 1598 & 78.4 & 15.2 \\
\hline 3 & The Sarray & 5996 & 30.6 & 602 & 195.9 & 19.6 \\
\hline 4 & Hattin & 16804 & 48 & 1016 & 350 & 21.1 \\
\hline 5 & Swamra & 9946 & 8 & 256 & 1243.2 & 32 \\
\hline 6 & Shifta & 6592 & 42 & 793 & 156.9 & 18.8 \\
\hline 7 & Bones mother. & 1699 & 11 & 249 & 154.4 & 22.6 \\
\hline 8 & Mustafa & 12683 & 78.3 & 1637 & 145.2 & 20.9 \\
\hline 9 & New Baquba & 8222 & 169.2 & 1832 & 48.5 & 10.8 \\
\hline 10 & Retail & 37855 & 44.8 & 1013 & 844.9 & 22.6 \\
\hline 11 & First Yarmouk & 19462 & 541.6 & 2743 & 35.9 & 5 \\
\hline 12 & Yarmouk Second & 51414 & 574.5 & 3647 & 89.4 & 6.3 \\
\hline 13 & Industrial Complex & 9755 & 82.5 & 897 & 118.2 & 10.9 \\
\hline 14 & First Tahreer & 44138 & 213.8 & 3798 & 206.4 & 17.7 \\
\hline 15 & Second Tahreer & 31235 & 228.2 & 2056 & 136.8 & 9 \\
\hline 16 & District teachers & 39891 & 81.5 & 1211 & 489 & 14.8 \\
\hline 17 & The Hakeem & 3192 & 345 & 729 & 9.25 & 2.1 \\
\hline & Total & $\mathbf{5 6 3 7 8 9}$ & $\mathbf{2 6 8 7 . 7}$ & & & \\
\hline
\end{tabular}


Table (2):Types of random urban expansions in the neighbourhoods of Baquba city in $2015^{(7)}$

\begin{tabular}{|c|l|c|c|c|}
\hline No. & Neighbourhood name & condominium units & $\begin{array}{c}\text { exceeded } \\
\text { individually }\end{array}$ & $\begin{array}{c}\text { Percentage of } \\
\text { residential units }\end{array}$ \\
\hline 1 & First Tekiya & 0 & 20 & 4.5 \\
\hline 2 & Second Tekiya & 0 & 4 & 7.4 \\
\hline 3 & The Sarray & 287 & 0 & 5.5 \\
\hline 4 & Hattin & 1016 & 8 & 0 \\
\hline 5 & Swamra & 215 & 19 & 6.9 \\
\hline 6 & Shifta & 782 & 0 & 0 \\
\hline 7 & Bones mother.Indust & 143 & 13 & 19 \\
\hline 8 & Mustafa & 753 & 14 & 17 \\
\hline 9 & New Baquba & 126 & 21 & 13.3 \\
\hline 10 & Retail & 176 & 33 & 9.9 \\
\hline 11 & First Yarmouk & 515 & 27 & 8.8 \\
\hline 12 & Yarmouk Second & 1918 & 7 & 7.7 \\
\hline 13 & Industrial Complex & 44 & 37 & 11 \\
\hline 14 & First Tahreer & 453 & 29 & 22 \\
\hline 15 & Second Tahreer & 389 & 0 & 5.2 \\
\hline 16 & Teachers & 10 & 55 & \\
\hline 17 & The Hakeem & 127 & & \\
\hline
\end{tabular}

